Final version:

Maon, F., Lindgreen, A., and Swaen, V. (2008), "Thinking of the organization as a system: the role of managerial perceptions in developing a CSR strategic agenda", Systems Research and Behavioural Science, Vol. 25, No. 3, pp. 413-426. (ISSN 1099-1743)

For full article, please contact LindgreenA@ cardiff.ac.uk

Thinking OF THE ORganization AS A SyStem:

The Role of Managerial Perceptions in Developing a Corporate Social ReSPONSIbILITy Strategic Agenda

\author{
François Maon $^{1}$ \\ Université catholique de Louvain, Belgium \\ Adam Lindgreen $^{2}$ \\ Hull University Business School, UK \\ Valérie Swaen ${ }^{34}$ \\ Université catholique de Louvain, Belgium
}

\footnotetext{
${ }^{1}$ Corresponding author: François Maon, Department of Marketing, IAG Louvain School of Management, Université catholique de Louvain, Place des Doyens 1, 1348 Louvain-la-Neuve, Belgium. Telephone: + 32 10478457. E-mail: francois.maon@uclouvain.be.

2 Adam Lindgreen, Professor of Strategic Marketing, Department of Marketing and Business Strategy, Hull University Business School, Cottingham Road, Hull HU6 7RX, the United Kingdom. Telephone: + 441482463096. E-mail: a.lindgreen@hull.ac.uk.

${ }^{3}$ Valérie Swaen, Assistant Professor of Marketing, Department of Marketing, Louvain School of Management, Université catholique de Louvain, Place des Doyens 1, 1348 Louvain-la-Neuve, Belgium. Telephone: + 32 10479156. E-mail: valerie.swaen@uclouvain.be.

${ }^{4}$ The authors thank Benoît Gailly and Nadine Fraselle for helping to collect data; they also thank the case organization.
} 
Thinking OF THE ORganization AS A SYSTEM:

\title{
The Role of Managerial Perceptions in Developing a Corporate Social
}

\author{
RESPONSIBILITY STRATEgIC AgENDA
}

\begin{abstract}
The societal issues conveyed to the organization by its internal and external stakeholders can be various and often conflicting. Consequently, organizations confront difficulties when attempting to identify the range of relevant societal issues they must prioritize to design corporate social responsibility (CSR) programs. This article proposes a conceptual framework to clarify the processes that underlie the emergence, prioritization, and integration of CSR issues into organizational goals. Specifically, this article uses systems thinking, CSR, and organizational interpretation theories to highlight the central influence of top managers' perceptions on the development of CSR strategic agendas.
\end{abstract}

Keywords: corporate social responsibility; individual perception; organizational interpretation; strategic agenda development. 


\title{
ThINKING OF THE ORganization AS A SYSTEM:
}

\section{The Role of Managerial Perceptions in Developing a CSR Strategic Agenda}

\author{
"Most of the mistakes in thinking are inadequacies of perception rather than mistakes of logic."
}

—Edward de Bono

\section{Introduction}

Environmental excellence and the well-being of people within and outside the organization increasingly represent issues that organizations must integrate into the core of their business strategy and practices. Beyond the traditional objectives of supplying services and goods, organizations encounter increasing pressures to address and respond to the societal issues arising from their activities. Managers face virtually constant demands from various groups to devote resources to corporate social responsibility (CSR) policies and initiatives (Pinkston \& Carroll 1994). These pressures arise not only from nongovernmental organizations (Doh \& Guay 2004), shareholder activists (O'Rourke 2003), business customers (Roberts 2003), socially responsible investors (Aslaksen \& Synnestvedt 2003), union federations (Egels-Zandén \& Hyllman 2006), and communities (Waddock \& Boyle 1995) but also from general societal trends, such as growing attention to ethical consumerism (Harrison et al. 2006) and institutional expectations (Waddock et al. 2002). Even industry peers and competitors can pressure organizations to make socially responsible decisions (Berry and Rondinelli, 1998).

Furthermore, perceived unethical or unsustainable corporate practices might "alienate the organization from the rest of society, resulting in reduced reputation, increased costs, and decreasing shareholder value through erosion of its license to operate" (Hill 2001, p. 32). In contrast, demonstrating responsible behavior can create substantial benefits through the development of positive attitudes toward the organization (McWilliams \& Siegel 2001; Sen et al. 2006; Turban \& Greening 1996) and its products (Brown \& Dacin 1997; Sen \& Bhattacharya 2001), as well as the development of competitive advantages (Porter \& Kramer 2006) and valuable organizational capabilities (Sharma \& Vredenburg 1998). Therefore, more and more organizations are developing CSR strategic agendas and implementing CSR-related initiatives. A CSR strategic agenda must establish the main CSR directions for the organization, the method by and extent to which CSR principles will be integrated in its structures and culture, and the plan of actions associated with CSR strategic choices.

However, CSR-related issues conveyed by internal and external stakeholders often are varied and conflicting. Organizations thus have trouble identifying the range of relevant societal issues they must address, as well as the priority with which they should do so. The development and implementation of integrated CSR strategic agendas by organizations therefore becomes a process of change that occurs through managerial understanding and sense making (Cramer et al. Jonker 2006). Each organization must develop its own meaning of CSR to clarify the motivation that underlies its commitments and identify the stakeholders and issues that represent key priorities (Maignan et al. 2006). During such a definition stage, the essential interactions with 
various stakeholder groups (Ilmolaa \& Kuusi 2006) require significant resources and appropriate organizational and managerial capabilities.

Furthermore, organizations can represent interpretation systems (Daft \& Weick 1984), such that constructing a CSR strategic agenda results from the translation of events and issues into shared understanding and conceptual schemes among upper managers. These managers, with their personal characteristics, then become key drivers of the design and implementation of CSRrelated initiatives. In turn, the central objectives of this research are to contribute to a better understanding of the organizational processes associated with considering and developing a CSR strategic agenda, as well as to recognize the role of managerial perceptions for these processes.

The remainder of this theoretical study is structured as follows: First, we highlight the importance of processes to identify CSR issues as a basis for developing coherent CSR initiatives. Second, we emphasize the relevance of a systems thinking perspective for the design and development of a CSR strategic agenda. In particular, we regard the organization as both a stakeholder system and an interpretation system. Third, we highlight the importance of managers' perceptions and personal characteristics during the process of recognizing and prioritizing the CSR issues that the organization faces. Fourth, on this basis, we suggest a model in which we conceptualize the development of a CSR strategic agenda with a systems-thinking perspective that emphasizes the role of upper managers. Fifth, we discuss the usefulness of the model through its application in a pharmaceutical company that is developing a CSR strategic agenda. Finally, we note some limitations of our work and discuss potential avenues for further research.

\section{Conceptual Framework: Understanding the Development of a CSR Strategic Agenda}

\section{Identifying CSR Issues as a Basis for Developing a CSR Strategic Agenda}

As a rich but still undefined concept, CSR encompasses a broad range of concerns (Carroll 1999; de Bakker et al. 2005; Garriga \& Melé 2004; Secchi 2007). According to the European Commission (2001, p. 6), CSR is "a concept whereby organizations integrate social and environmental concerns in their business operations and in their interactions with their stakeholders on a voluntary basis." Thus, it includes concerns and issues related to human rights, people's well-being at work, environmental impacts, business ethics, community investments, governance, and the marketplace (e.g., Maignan \& Ralston 2002).

Yet CSR cannot mean the same thing to everyone, because CSR issues "vary by business, by size, by sector and even by geographic region" (Business for Social Responsibility 2003). In addition, complex CSR issues involve multifaceted networks of stakeholders whose conceptions of responsible organizations vary across both groups and individuals (Zyglidopoulos 2002). Stakeholders' CSR expectations may be inconsistent (Dawkins \& Lewis 2003) and inexorably evolve over time (Polonsky \& Jevons 2006). A responsible initiative today may become a potentially harmful action in the future (Polonsky \& Rosenberger 2001).

As a result, any organization trying to embrace CSR must recognize that "the subject can easily be interpreted as including almost everyone and everything" (WBCSD 2001). Identifying 
appropriate CSR issues therefore entails a tricky task. To respond to societal expectations and allocate resources, organizations must first identify relevant CSR issues so that they can develop their CSR strategic agenda. Thereafter, CSR issues and related organizational practices demand constant reassessments. Thus, the task of management is to understand the past, current, and future operating environments of the organization (Renfro 1993). A systems perspective provides a relevant foundation for such tasks.

\section{Adopting a Systems Perspective to Developing a CSR Strategic Agenda}

Systems thinking involves seeing the world not as discretely compartmentalized units but rather as a network of overlapping and interrelated elements (Reich 1992), that is, "seeing interrelationships rather than things, ... seeing patterns of change rather than static snapshots" (Senge 1990, p. 68). Systems thinking focuses on recognizing the interconnections among the various parts of a system and then synthesizing them into a cohesive view of the whole (Anderson \& Johnson 1997).

From a systems viewpoint, organizations are open social systems that must cope with environmental and organizational uncertainty, as well as develop characteristics and perform processes that enable them to adapt to the opportunities, threats, and constraints that constitute the environment and society (Tushman \& Nadler 1978). Because they are influenced by external forces and environmental conditions, organizations cannot control their own behaviors entirely (Cummings \& Worley 2004). Adopting an open social system perspective, we assert that organizations should be regarded as specific systems of stakeholders (Vos 2003) and of interpretations (Daft \& Weick 1984). Furthermore, similar to Gregory and Midgley (2003), we regard systems thinking as a necessary perspective that enables an organization to comprehend and respond to rising concerns about CSR issues at local, regional, and international levels.

Organizations as stakeholders' systems

From a systems viewpoint, the open system of stakeholders that constitutes an organization operates "within the larger system of the host society that provides the necessary legal and market infrastructures for the firm's activities" (Clarkson 1994, p. 21).

Furthermore, according to stakeholder theory, organizations have a moral duty to take stakeholders' concerns into consideration (Evan \& Freeman 1993), which means addressing the concerns of "any individual or group who can affect or is affected by the actions, decisions, policies, practices, or goals of an organization" (Gatewood \& Carrol 1991, p. 673; adapted from Freeman 1984). Stakeholder groups that convey their societal expectations to organizations may include owners and investors, customers, suppliers, managers and employees, competitors, the local community, government, and the media. Such groups often form coalitions that "have more influence than a stakeholder alone" (Vos 2003, p. 142). Consequently, organizations need a reliable mechanism to identify the relevant coalitions and related issues and then define the clear limits of the stakeholder system that it represents.

Critical systems thinking can help resolve the managerial problem of identifying stakeholder coalitions and issues (Achterkamp \& Vos 2007; Vos 2993). On the basis of critical systems heuristics (see Ulrich, 1983, 1988) and considering a case of specific innovation projects (rather 
than focusing on organizations as a whole), Achterkamp and Vos (2007) propose a four-phase method-initiation, development/performance, implementation, and maintenance-for identifying stakeholders according to their level and timing of involvement with regard to a particular project.

We apply this method to the problem of identifying CSR stakeholders. Thus, each key CSR issue the organization faces represents a project to manage. For example, an innovation project might try to adapt existing procedures by modifying suppliers' auditing practices to address human rights issues; another project could develop new processes linked to a particular CSR issue, such as developing innovative solutions to reduce carbon dioxide emissions; or projects could pertain to the cultural evolution as the organization attempts to design long-term education programs to sensitize workers to sustainability issues. The CSR strategic agenda that results from such an approach would regroup different projects according to whether they appear decisive and coherent with corporate goals.

However, to develop a consistent CSR strategic agenda, organizations must recall that CSR does not simply entail various, disconnected issues. Rather, it pertains to doing some good by developing several interconnected initiatives that help manage the relationships that are central to the future success of the organization and resolve any dilemmas among the competing interests of stakeholders (Werther \& Chandler 2006). Consequently, projects that constitute the CSR strategic agenda must achieve moving equilibrium and help build mutually beneficial relationships with key stakeholders; no part of the system can persist if it lacks equilibrium with other parts. The interrelationships among CSR issues and their related projects therefore must be recognized to enable the organization to design a constructive and coherent CSR strategic agenda. Furthermore, this perspective demands a sound understanding of each key issue, as well as an organizational mindset that appreciates the complexities of the environment.

\section{Organizations as interpretation systems}

To identify the key coalitions of stakeholders, the decisive CSR issues, and their interrelationships, organizations should develop information processing mechanisms they may use to detect events, trends, and developments that are relevant to their activities. To "know" the environment, they must develop internal scanning processes that "identify emerging issues, situations, and potential pitfalls that may affect [their] future" (Albright 2004, p. 40). Environmental data then require interpretation (Daft \& Weick 1984) to translate them into knowledge and understanding before the organization can determine whether and how to respond to a potentially critical CSR issue. Ashmos et al. (1998) note that such decision making requires knowledge of which stakeholders possess information that can help resolve a specific issue and which groups should participate in the decision-making process.

Identifying these key issues and coalitions of stakeholders requires managers to listen to, look for, and show consideration for stakeholders' limits (Bowen \& Heath 2005). Organizational mechanisms for apprehending the environment, processing information, and setting goals cannot be divorced from the individuals who possess these capabilities (Daft \& Weick 1984). In this sense, the organization's interpretation of environmental data and subsequent decisions depend on how managers perceive the interdependencies among stakeholder systems. When managers share interpretations, they create an overriding organizational interpretation. 


\section{Central Influence of Managers' Perceptions in Developing a CSR Strategic Agenda}

Managers interpret the signals sent by the environment (Hegarty \& Thianyi 1999) and determine the resulting organizational responses (Child 1972; Mitchell et al. 1997); that is, their interpretations form the basis for organizational decisions. Managerial perceptions ${ }^{5}$ thus might be considered "the substratum that business decisions feed upon" (Santos and Garcia 2006, p. 752). In this substratum, managers' personal characteristics play key roles in defining corporate strategic orientations. To interpret stakeholders' expectations of their organization, managers "must wade into the ocean of events that surround the organization and actively try to make sense of them" (Daft and Weick 1984, p. 206).

Yet managers, as humans, perceive their environment both uniquely and imperfectly. Because they are subject to various inevitable biases, their perceptions provide only a flawed reflection of the environment. In particular, managers interpret selective information through the filter of their own values (Rokeach 1973) and cognitive predispositions. Furthermore, their bounded rationality limits their ability to apprehend the full complexity of the business world (Simon 1957), restricting their perceptions to the phenomena that appear in the limited field of their vision. In turn, managers' perceptions "may diverge significantly when witnessing the same event" (Santos \& Garcia 2005, p. 753), and no manager can fully comprehend the complex systems that characterize organizational activities.

Previous studies illustrate that relevant managerial interpretations of the environment can contribute to the success of an organization by improving performance (Downey et al. 1975; Hegarty \& Tihanyi 1999; Miller 1993). Misinterpretation, however, leads to performance deterioration and crises (Milliken 1990).

The role of upper management perceptions

Previous research confirms that personal characteristics and backgrounds influence people's level of social involvement (e.g., Borkowski \& Ugras 1992; Burton \& Hegarty 1999).

Because CSR corporate commitments are extensively "maintained, nurtured and advanced by the people who manage them" (Quazi 2003, p. 822), individual drivers such as beliefs, values, demographics, educational and cultural backgrounds, and personal attributes play significant roles in shaping managers' perceptions about societal issues and CSR strategic agendas (e.g., Campbell et al. 1999; Deshpande 1997; Hemingway \& Maclagan 2004; Menon \& Menon 1997; Quazi 2003; Thomas \& Simerly 1994). For example, women tend to demonstrate a higher CSR orientation (Burton \& Hegarty 1999); more risk-averse managers are less inclined to invest in enviropreneurial marketing strategies (Campbell et al. 1999); and managers with more experience demonstrate a superior ability to develop and implement relevant policies to meet stakeholders' needs (Thomas \& Simerly 1994). Thus, managers and their personal characteristics dictate the strategy toward and modes of corporate responses to environmental expectations and demands (Wood 1991).

\footnotetext{
${ }^{5}$ Perception refers to "the dynamic psychological process responsible for attending to, organizing, and interpreting sensory data” (Buchanan \& Huczynski 1997, p. 46).
} 
Acknowledging the central influence of managers' perceptions and interpretations when designing strategic agendas, Thomas and Simerly (1994) show that upper managers play an especially decisive role in articulating the strategic posture of the organization. The key influence of upper versus middle managers mirrors Bedeian's (2002) claims that middle management reflects top managers' values, knowledge bases, and understanding, because they usually get promoted on the basis of their persistent support of top management perspectives. Further research confirms that upper managers - who are responsible for overseeing and guiding the organization to success through their strategic, long-term decisions-exert the central influence on the development and implementation of an organization's CSR orientation (e.g., Banerjee 2001; Maxwell et al. 1997; Waldman et al. 2006).

Because of the role played by upper managers in defining the organization's CSR orientation, the CSR strategic agenda must be subject to diverse subjective perceptions that determine its ultimate form. Convergence among such diverse perceptions is critical as a means to organize and design the policies of an organization (Weick 1979); moreover, it enables the organization to "interpret as a system" (Daft \& Weick 1984, p. 285). Coherence among managers' perceptions thus establishes the organization's interpretation of CSR issues and affects its responsiveness to those issues. This coherence further depends on the organization's interpretative frame, which results from its unique features and culture (Bowen \& Heath 2005).

\section{Understanding the Development of a CSR Strategic Agenda: A Dual Loop Model}

The preceding theoretical background leads us to suggest a comprehensive conceptual framework for understanding how CSR strategic agendas are developed and implemented by organizations (see Figure 1).

Our descriptive model consists of two sequential loops, interconnected by two central elements: (1) managerial perceptions of CSR issues and their importance and (2) the resulting convergence of these managerial perceptions into an organizational interpretation, leveraged by existing organizational attributes and features. In large organizations, convergence often requires an established CSR committee or department (e.g., Beadle \& Donnelly 2004; Walker 2005), composed of key managers who debate and prioritize CSR issues. Such committees usually deal with and evaluate the relevance of CSR issues for the business and culture of the organization, orient the CSR strategic agenda, and coordinate CSR initiatives within the various components of the organizational system.

The first loop of our model, the stakeholder dialogue loop, refers to the process of interaction between the organization and its stakeholders. Through this process, stakeholders can express their views about CSR issues through a structured exchange (Stoll-Kleemann \& Welp, 2006) on a continuous (or at least regular) basis. Such dialogue influences managers' perceptions of the external environment and generates greater awareness of the CSR issues at stake. Feedback during the stakeholder dialogue process eventually influences managers' personal perceptions of CSR issues and their relevance for the organization. In this sense, an organization can obtain no more important information than feedback from its environment (Krippendorf \& Eleey 1986). 
The constructive nature of stakeholder dialogue and feedback depends, however, on the resources initially invested in the process.

The second loop of our model, the CSR integration loop, addresses the development and implementation of key CSR initiatives. Specifically, upper managers provide their perceptions of CSR issues, which become the organizational interpretation, which in turn serves as the basis for the CSR strategic agenda. From a strategic planning perspective, upper managers typically assess the organization's internal CSR strengths and weaknesses, evaluate alternative strategies, and then develop action plans. Implementing CSR initiatives and perceptions about the fulfillment of strategic objectives eventually influence upper managers' perceptions of the various CSR issues and their importance.

Finally, perceived stakeholder feedback combines with the perceptual outcomes of CSR-related initiatives and influences managers' perceptions of CSR issues and their importance, percolated though the filter of their personal values, beliefs, and characteristics. This process induces a better understanding of current issues and the identification of new CSR issues. It also demands recurrent adaptations to the organization's CSR strategic agenda. Our model further highlights the need to establish efficient procedures to initiate CSR strategic agenda development. This issue is especially critical in organizations that lack any structured CSR policies or systematic CSR-related scanning processes; for these organizations, managers' awareness, knowledge, and perceptions likely are severely restricted or, at the very least, tacit and unshared. 
FIGURE 1: A dual loop model for understanding the development of a CSR strategic agenda

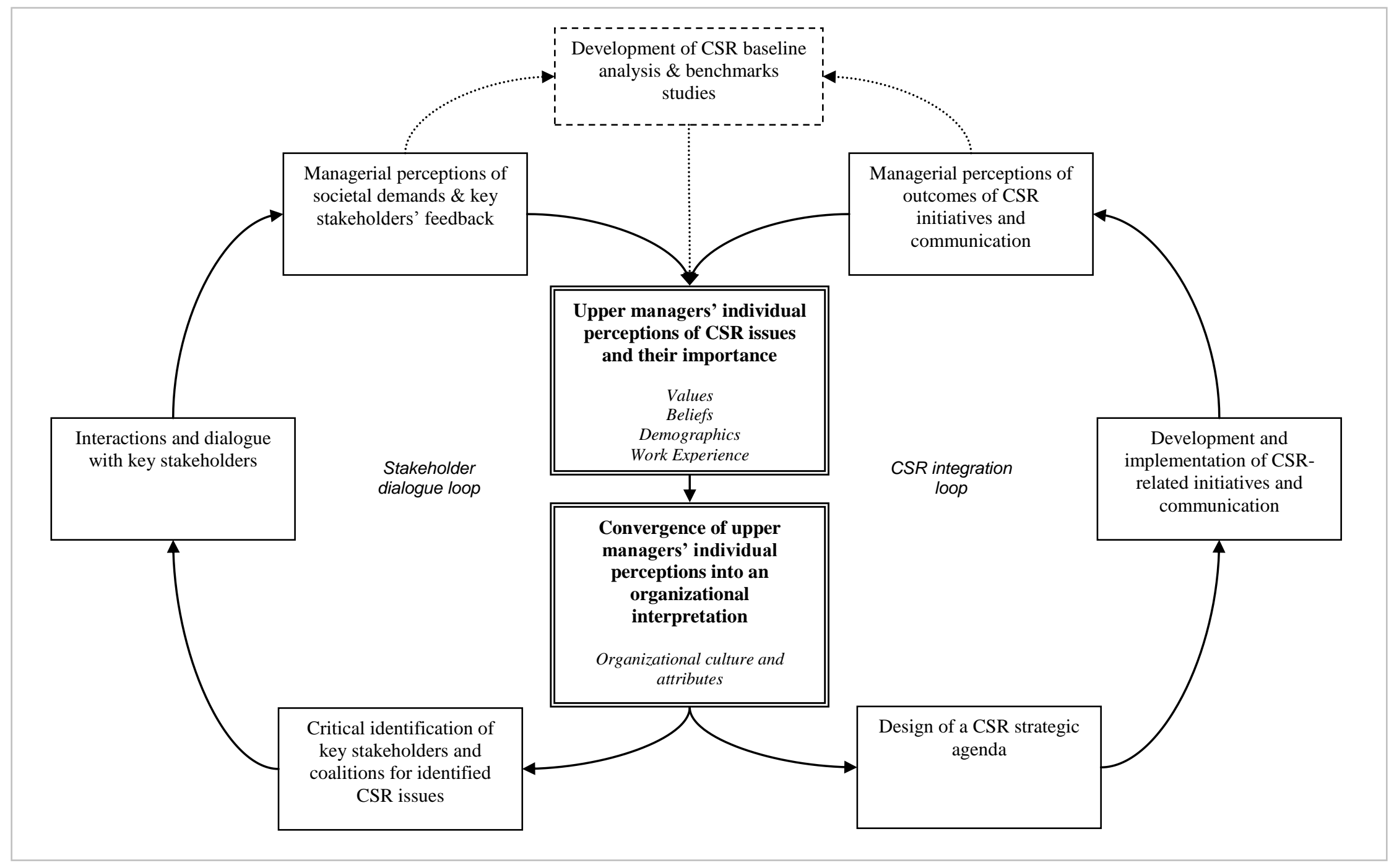




\section{Empirical usefulness of the suggested model}

To assess the usefulness of the suggested model, we develop a partnership with a large, autonomous subsidiary of a multinational pharmaceutical company. The subsidiary already had implemented some CSR-related initiatives but without a clear vision or any coherence or coordination among the different initiatives.

Action research undertaken during a four-month period (January-April 2007) pursues the following objectives: to (1) assess the status of CSR within the company, (2) raise CSR awareness among upper managers, and (3) propose guidelines for developing an integrated and structured CSR orientation. To reach these objectives and initiate the process of CSR-oriented thinking within the organization, we apply the suggested model by collecting various sources of information about the company's CSR initiatives, upper managers' perceptions of CSR and relevant issues, and organizing different meetings with upper managers about CSR.

First, 13 upper managers (from 12 distinct functional departments) received a generic questionnaire to provide their pre-diagnosis of CSR. To select the appropriate managers, we considered their work experience, function within the organization, and membership in distinct departments. This pre-diagnosis questionnaire provides a review CSR practices by articulating 120 items in nine sections: (1) well-being at work and social responsibility toward staff, (2) company's involvement in the community, (3) top management's dedication to CSR principles, (4) workers' education and training with respect to CSR issues, (5) company's organization and structure, (6) CSR-related normative aspects and commitments, (7) CSR-related procedures and documentation, (8) CSR performance indicators, and (9) crisis and nonconformity management. In the next step, we interviewed these 13 upper managers to determine their conception of CSR practices and highlight CSR dimensions and concerns that they considered missing from the prediagnosis questionnaire. With this first data collection, we outline the organization's perception of performance with regard to common CSR aspects and, more important, gain an overview of the different managers' opinions about CSR issues.

Managers' perceptions about the CSR concept depend on their functional orientation and field of managerial knowledge. The CSR issues identified as critical for the company tend to demonstrate this function bias and vary according to the upper manager interviewed. This result is coherent with prior literature in the broader strategic management field; that is, managers perceive the elements of a situation that relates more specifically to the activities and goals of their own department (Dearborn \& Simon 1958).

Upper managers whose function tends to be externally oriented - such as marketing and external relations - consider the CSR concept from an instrumental and self-protective perspective, with a focus on image and reputation:

I essentially look at the CSR concept in a commercial way. What I think is interesting is the corporate image. What matters to me is first and foremost that the corporate reputation is good and that we don't have any trouble with clients, and that we don't find us represented as ruffians in the press (marketing manager). 
Managers in production and financial functions instead associate the concept of CSR with normative and regulatory requirements, as well as with the impact of noncompliance or negligent behaviours on the company:

For me, it [the CSR concept] is primary linked to compliance with norms legislations. Since we operate in a highly regulated environment, we must be considered as an organization that respects the rules. Afterwards, we should consider whether we go further. In all cases, potential deficiencies must not affect our core business (finance manager).

By contrast, upper managers from departments that deal with functional issues more clearly linked to CSR concerns - such as human resources or the environment, health, and safety departments-demonstrate more consideration for the impact of organizational activities on the social and ecological environment, both within and outside the organization, and refer more systematically to the duties associated with the stakeholders of the organization:

I think CSR can be considered as the capacity of the organization to take its responsibilities toward the various actors who intervene within the framework of organizational activities. I would say that the first actors to be taken into account are the workers, and then comes the shareholders, and what is generally defined by the general term of 'community.' The community includes people, neighbors, and the ecological environment (environment, health, and safety manager)

From a research and development viewpoint, the concept of CSR appears more directly apprehended into a "finality" perspective. That is, these managers consider the nature of the business activities and the products and services offered as the first vector of social responsibility for the organization:

Even if we remain an organization with commercial objectives, our CSR activities are primarily related to the development of products aimed at providing a greater well-being to the people who need them (research and development manager).

On the basis of this pre-diagnosis questionnaire and the subsequent interviews with upper managers, we identify two distinct categories of CSR issues that the organization must address: generic issues, which are essential to any organization in the process of developing an integrated CSR approach, and industry-specific issues. First, generic CSR issues include (1) dialogue and engagement with stakeholders and community; (2) organizational CSR culture and leadership; (3) managing environmental, health and safety concerns; and (4) employment practices. Second, six main CSR issues relate specifically to the ethical and managerial issues of the pharmaceutical industry: (1) access to medicines for needy persons, (2) specific quality management concerns, (3) clinical trials and publication of their results, (4) responsible product design, (5) responsibility in the procurement chain, and (6) promotion of products and marketing ethics.

Figure 2 illustrates how these two distinct categories of CSR issues articulate across the central spheres of the activities of the business organization-production, sales and marketing, and research and development - in the case of our pharmaceutical organization. 
FIGURE 2: Key CSR issues in the three spheres of business activity in the case company

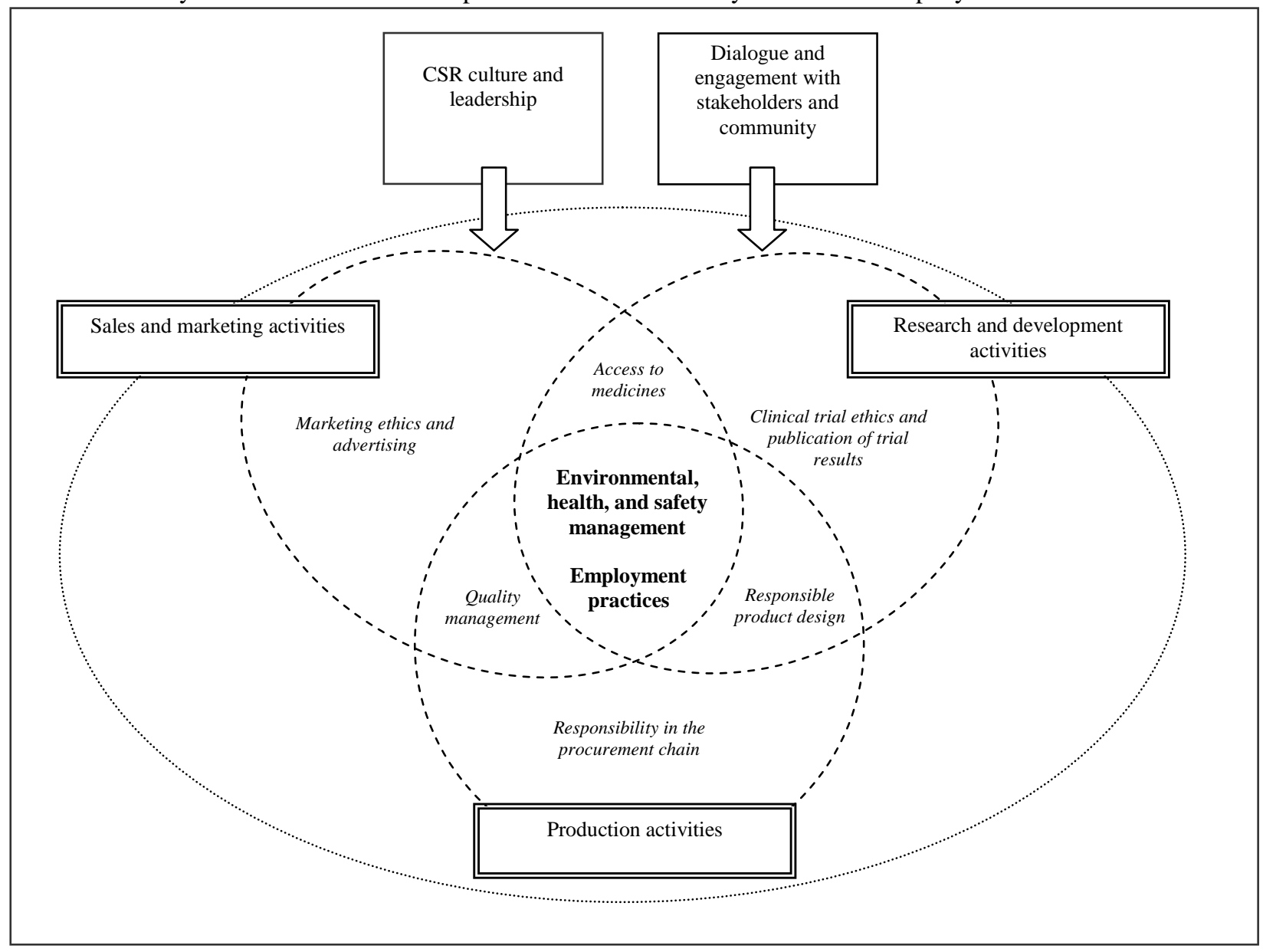

To assess the subsidiary organization's CSR position and perhaps highlight some best practices in the industry, we next undertake a benchmarking study of the CSR actions and policies of key players within the competitive environment. We also assess another specific organization with an excellent reputation in CSR-related matters within the broader industry.

The benchmarking study based on publicly available data (annual and sustainability reports, corporate communication, press releases, articles) highlights several areas in which the focal subsidiary might improve in terms of environmental, health, and safety management (i.e., it has no systematic policy to design environmentally friendly products; it has suffered frequent accidents or incidents, despite significant improvements in recent years); employment practices (i.e., no satisfaction survey, growing psycho-social pressures); the development of a CSR culture (i.e., absence of explicit CSR policy, and no financial and human resources dedicated specifically to CSR issues); and dialogue with external stakeholders (cf. punctual discussions generated by daily business).

During participative meetings, the interviewed managers received the findings from the prediagnosis, interviews, and benchmarking studies; they offer personal perceptions of these findings and arrive at a common interpretation of the identified CSR issues and their importance, which provides refinement and validation of the findings. Convergence between the managers' 
perceptions of key CSR issues emerged progressively through discussions and debates during the meetings. A comprehensive map of the CSR issues that the company faces finally resulted from this process, from which a CSR strategic agenda could progressively be built. In response, the subsidiary designated a CSR champion and initiated some CSR projects, including assessing external stakeholders' perceptions about its CSR posture, integrating key stakeholders into reflections about CSR issues, and designing a structured CSR external communication scheme.

According to our model (Figure 1), the action research led to a systematic inventory of existing CSR engagements, as well as the definition of key axes of development for a CSR strategic agenda. The outcomes of the action research further highlight how an organization can rely on diversified internal managerial perceptions and know-how to identify key CSR-related issues and establish its current CSR status. Finally, this case study enables us to suggest simple and practical recommendations in terms of internal processes that companies should develop:

1. A designated CSR facilitator should initiate CSR status analyses and supervise subsequent steps of the process.

2. Because managers reveal a function-biased understanding of the meaning of CSR in their organization, efforts to identify CSR issues thoroughly require the combination and convergence of different managerial perspectives to establish a comprehensive basis for developing the CSR strategic agenda. This requirement in turn demands that the organization identify key upper managers within the distinct functional departments of the organization who have significant know-how about organizational features and culture. All key functional departments should be represented to leverage the comprehensive examination of potential CSR issues faced by the organization.

3. Because CSR issues vary from one industry to the other, the company's CSR positioning must be benchmarked continuously within the sector of industry activities, with a simultaneous, continuous search for best practices in generic CSR issues, even outside that sector of activities. The relative strengths and weaknesses of an organization with respect to CSR generic and industry-specific issues should be evaluated through a simple rating process, such as below average performance, average performance, and upper average performance.

4. Meetings pertaining to CSR issues that involve managers from different functional areas should be organized to reach progressive convergence among managers' perceptions of CSR issues priority and to develop a commonly shared CSR strategic agenda.

5. Not only should a CSR champion be designated within the organization, but a CSR committee should take charge of developing a structured CSR strategic agenda on the basis of the awareness and potential strategic lines provided by the simple CSR mapping process developed in the previous steps.

\section{Discussion and Conclusion}

Most organizations confront environments that continue to grow more complex, unpredictable, and multifaceted. Because stakeholders convey "a variety of conflicting values and interests" (Lozano, 1996, p. 233), organizations face serious challenges in their efforts to identify and prioritize the range of societal issues they should address. In particular, developing a CSR strategic agenda can be a challenging task. 
In this context, we offer three main contributions. First, we provide a better understanding of the processes and rationales that underlie the development of a CSR strategic agenda. By integrating systems thinking, CSR, and organizational interpretation theories, we offer the first comprehensive conceptual framework to highlight how CSR issues emerge, get prioritized, and become integrated into organizational goals. Moreover, the systemic nature of the continuous process we imagine requires organizations to design structured dialogue with their stakeholders and efficient monitoring systems if they want to implement CSR strategic objectives. In accordance with Hebel and Davis (2005, p. 526), our framework emphasizes that at all points during the development process toward a CSR orientation, "the requirements of the various stakeholders involved must be accounted for, matched or adapted according to need in order to achieve the required development." Furthermore, we specify that organizations must find ways to scan their environments regularly to identify potential key CSR issues, as well as societal and business demands.

Second, we note the critical role of upper managers and their perceptions during the development of a structured CSR-related agenda. Together, these elements contribute to an innovative perspective into the development of CSR strategic agendas by contemporary organizations.

Third, findings from the action research portion of our study confirm that existing managerial knowledge within an organization constitutes a strong basis for initiating a CSR strategic agenda. Specifically, our findings highlight how different perceptions about CSR by various managers from various departments must complement one another if the company hopes to identify its CSR status comprehensively. Our findings further emphasize that CSR issues systematically consist of two distinct groups pertaining to generic and industry-specific CSR concerns.

However, our article is not exempt from limitations. First, our conceptual framework requires further empirical support, perhaps with specific case studies that could provide relevant insights. Second, by emphasizing the central role of upper managers' perceptions, we may limit potential constructive inputs from the organization's main stakeholders. However, our study conceives of CSR development primarily as an organizational, strategic, or moral option, initiated by the organization and the people who manage it. This organization may be subject to multiple constraints and pressures from multiple actors, but its chief constraints involve its own resources and capabilities. Thus, though our intent certainly is not to underestimate the power and influence of key stakeholders, our conceptual framework focuses on reaffirming the role of the subjective human factor in the dynamic processes of responding to the environment and developing CSR initiatives.

Any successful process to develop organizational strategic initiatives and policies must rely on a comprehensive understanding of the issues that the organization faces. This proscription is not specific to the case of CSR. However, for CSR in particular, organizations benefit when they achieve a cohesive definition of the issues they must consider (Jaques 2006). Developing CSR involves a long, continuous process, and establishing a solid foundation for the coherent agenda represents a prerequisite for any constructive initiative. We hope our article contributes to such ends for organizations.

\section{Acknowledgments}


The authors contributed equally. They thank Benoit Gailly and Nadine Fraselle for helping to collect data; they also thank the case organization. 


\section{References}

Achterkamp, M. C., and Vos, J. F. 2007. Critically identifying stakeholders: evaluating boundary critique as a vehicle for stakeholder identification. Systems Research and Behavioral Science, 24(1): 3-14.

Albright, K. S. 2004. Environmental scanning: radar for success. The Information Management Journal, 38(3): 38-45.

Anderson, V., and Johnson, L. 1997. Systems thinking basics: from concepts to causal loops. Waltham, MA: Pegasus press.

Ashmos, D.P., Duchon, D., and McDaniel, R. R. 1998. Participation in strategic decision making - the role of organizational predisposition and issue interpretation. Decision science, 29(1): 25-51.

Aslaksen, I., and Synnestvedt, T. 2003. Ethical investment and the incentives for corporate environmental protection and social responsibility. Corporate Social Responsibility and Environmental Management, 10(4), 212-223.

Banerjee S. B. 2001. Managerial perceptions of corporate environmentalism: Interpretations from industry and strategic implications for organizations. Journal of Management Studies, 38(4): 489-513.

Beadle, R., and Donnelly, N. 2004. Linking reports to action at British American Tobacco. Corporate Responsibility Management, 1(1):30-33.

Bedeian, A. G. 2002. The dean's disease: how the darker side of power manifests itself in the office of the dean. Academy of Management Learning and Education, 1(2): 164-173.

Berry, M. A., and Rondinelli, D. A. 1998. Proactive corporate environment management: A new industrial revolution. Academy of Management Executive ,12(2): 38-50.

Bowen, S. A, and Heath, R. L. 2005. Issue management, systems, and rhetoric: exploring the distinction between ethical and legal guidelines at Enron. Journal of Public Affairs, 5(2): 8498.

Brown, T., and Dacin, P. (1997). The company and the product: corporate associations and consumer product responses. Journal of Marketing, 61: 68-84.

Buchanan, D., and Huczynski, A. 1997. Organizational behaviour: An introductory text, $3^{\text {rd }}$ ed. London: Prentice-Hall Europe.

Borkowski, S. C., and Ugras, Y. J. 1998. Business students and ethics: a meta-analysis. Journal of Business Ethics, 17(11): 1117-1127.

Burton, B. K., and Hegarty, W. H. 1999. Some determinants of student corporate social responsibility orientation. Business and Society, 38: 188-205.

Business for Social Responsibility. 2003. Overview of corporate social responsibility, BSR Issue Brief, available at http://www.bsr.org/insight/issue-brief-details.cfm?DocumentID=48809.

Campbell, L., Gulas, C. S., and Gruca, T. S. 1999. Corporate giving behaviour and decision maker social consciousness. Journal of Business Ethics, 19(4), 375-83.

Carroll, A. B. 1999. CSR: evolution of a definitional construct, Business and Society, 38(3), 268295.

Child, J. 1972. Organizational structure, environment and performance: the role of strategic choice. Sociology, 6(1): 1-22.

Clarkson, M. 1994. A risk based model of stakeholder theory. Proceedings of the Second Toronto Conference on Stakeholder Theory. Toronto, CA: Centre for Corporate Social Performance\& Ethics, University of Toronto. 
Cramer, J. M., van der Heijden, A. J. W., and Jonker, J. 2006. Corporate social responsibility: making sense through thinking and acting. Business Ethics: A European Review, 15(4): 380389.

Cummings, T., and Worley, C. 2004. Organization development and change, 8th ed. Cincinnati, $\mathrm{OH}$ : South-Western College Publishing.

Daft, R., and Weick, K. 1984. Toward a model of organizations as interpretation systems. Academy of Management Review, 9(2): 284-295.

Dawkins, D., and Lewis, S. 2003. CSR in stakeholder expectations and their implication for company strategy. Journal of Business Ethics, 44(2/3): 185-193.

Dearborn, D. and Simon. H. 1958. Selective perception: A note on the department identifications of executives. Sociometry, 2(2): 140-144.

De Bakker, F., Groenewegen, P., and Den Hond, F. 2005. A bibliometric analysis of 30 years of research and theory on corporate social responsibility and corporate social performance. Business \& Society, 44(3): 283-317.

Deshpande, S. P. 1997. Managers' perception of proper ethical conduct: the effect of sex, age and level of education. Journal of Business Ethics, 16(1): 79-85.

Doh, J. P., and Guay, T. R. 2004. Globalization and corporate social responsibility: how nongovernmental organizations influence labor and environmental codes of conduct. Management International Review, 44 (2): 7-30.

Downey, H. K., and Slocum, J. W. Jr. 1975. Uncertainty: measures, research, and sources of variation. Academy of Management Journal, 18(3): 562-578.

Egels-Zandén, N., and Hyllman, P. 2006. Exploring the effects of union-NGO relationships on corporate responsibility: the case of the Swedish clean clothes campaign, Journal of Business Ethics, 64(3): 303-316.

European Commission. 2001. Promoting a European framework for corporate social responsibility. Green Paper, Luxembourg: Office for Official Publications of the European Communities.

Evan, W., and Freeman, R.E. 1988. A stakeholder theory of the modern corporation: Kantian capitalism, in: Beauchamp, T., and Bowie, N. (Eds.). Ethical theory and business, 3rd ed., Englewood Cliffs: Prentice-Hall: 101-105.

Freeman, R. E.1984. Strategic management: a stakeholder approach. Boston, MA: Pitman.

Garriga, E., \& Melé, D. 2004. Corporate social responsibility theories: mapping the territory. Journal of Business Ethics, 53 (1-2): 51-71.

Gatewood, D., and Carroll, A. B. 1991. Assessment of ethical performance of organization members: a conceptual framework. Academy of Management Review, 16(4): 667-690.

Greenwood, D. and Morten Levin. 1998. Introduction to Action Research: Social Research for Social Change. Thousand Oaks: Sage.

Gregory, W., and Midgley, G. 2003. Systems thinking for social responsibility. Systems Research and Behavioral Science, 20(2): 103-105.

Harrison, R., Newholm, T. and Shaw, D. 2006. The ethical consumer. London, UK: Sage.

Hebel, M., and Davis, C. 2005. Determining value in organizations: myths, norms, facts and values. Systems Research and Behavioral Science. 22(6): 525-536.

Hegarty, W. H., and Tihanyi, L. 1999. Surviving the transition: Central European bank executives' view of environmental changes: a metamorphosis model of convergence and reorientation. Journal of World Business, 34(4): 409-422.

Hemingway, C. A., \& Maclagan, P. W. 2004. Managers' personal values as drivers of corporate social responsibility. Journal of Business Ethics, 50(1): 33-44. 
Hill, J. 2001. Thinking about a more sustainable business: an indicators approach. Corporate Environmental Strategy, 8(1): 30-38.

Ilmolaa, I., and Kuusib, O. 2006. Filters of weak signals hinder foresight: monitoring weak signals efficiently in corporate decision-making. Futures, 38(8): 908-924.

Jaques, T. 2006. Issue definition: the neglected foundation of effective issue management. Journal of Public Affairs, 4(2): 191-200.

Krippendorf, K., and Eleey, M. I. 1986. Monitoring a group's symbolic environment. Public Relations Review, 12(1): 13-36.

Lozano, J. M. 1996. Ethics and management: a controversial issue. Journal of Business Ethics, 15(2): 227-236.

Maignan, I., Ferrell, O. C., and Ferrell, L. 2006. A stakeholder model for implementing social responsibility in marketing. European Journal of Marketing, 39(9-10): 956-976.

Maignan, I., and Ralston, D. 2002. Corporate social responsibility in Europe and the U.S.: insights from businesses' self-presentations. Journal of International Business Studies, 33: 497-514.

Maxwell, J., Rothenberg, S., Briscoe, F., and Marcus, A. 1997. Green schemes: Corporate environmental strategies and their implementation. California Management Review, 39(3): 118-134.

McWilliams, A., and Siegel, D. 2001. Corporate social responsibility: a theory of the firm perspective. Academy of Management Review, 26(1): 117-227.

Menon, A., and Menon, A. 1997. Enviropreneurial marketing strategy: the emergence of corporate environmentalism as market strategy. Journal of Marketing, 61(1): 51-67.

Miller, K. D. 1993. Industry and country effects on managers' perception of environmental uncertainties. Journal of International Business Studies, 24(4): 693-714.

Milliken, F. J. 1990. Perceiving and interpreting environmental change: an examination of college administrators' interpretation of changing demographics. Academy of Management Journal 33(1): 42-63.

Mitchell, R. K., Agle, B. R., and Wood, D. J. 1997. Toward a theory of stakeholder identification and salience: defining the principle of who and what really counts. Academy of Management Review, 22(4): 853-886.

O'Rourke, A. 2003. A new politics of engagement: shareholder activism for corporate social responsibility. Business Strategy and the Environment, 12: 227-239.

Pinkston, T. S., and Carroll, A. B. 1994. Corporate citizenship perspectives and foreign direct investment in the U.S. Journal of Business Ethics, 13(3): 157-169.

Polonsky, M., and Jevons, C. 2006. Understanding issue complexity when building a socially responsible brand. European Business Review, 18(5): 340-349.

Polonsky, M., and Rosenberger, P. 2001. Re-evaluating to green marketing: an integrated approach. Business Horizons, 44(5): 21-30.

Porter, M. E. \& Kramer, M. R. 2006. Strategy and society: the link between competitive advantage and corporate social responsibility. Harvard Business Review, 84(12): 78-92.

Quazi, A. M. 2003. Identifying the determinants of corporate managers' perceived social obligations. Management Decision, 41(9): 822-831.

Reich, R. 1992. The work of nations: preparing ourselves for $21^{\text {st }}$ Century capitalism. New York: Vintage.

Renfro, W. 1993. Issues management in strategic planning. Westport, CT: Quorum books.

Roberts, S. 2003. Supply chain specific? Understanding the patchy success of ethical sourcing initiatives. Journal of Business Ethics, 44(2/3): 159-170. 
Rokeach, M. 1973. The nature of human values. New York: Free Press.

Santos, M. V., and Garcia, M. T. 2006. Managers' opinions: reality or fiction: a narrative approach. Management Decision, 44(6): 752-770.

Secchi, D. 2007. Utilitarian, managerial and relational theories of corporate social responsibility. International Journal of Management Reviews, 9(4): 347-373.

Sen, S., and Bhattacharya, C. B. 2001. Does doing good always lead to doing better? Consumer reactions to corporate social responsibility. Journal of Marketing Research, 38(2): 225-243.

Sen, S., Bhattacharya, C. B., and Korshun D. 2006. The role of corporate social responsibility in strengthening multiple stakeholder relationships: a field experiment. Academy of Marketing Science Journal, 34(2): 158-166.

Senge, P. 1990. The fifth discipline: the art and practice of the learning organization. New York: Doubleday.

Simon, H. 1957. Administrative behaviour. New York: The Free Press.

Sharma, S., and Vredenburg, H. 1998. Proactive corporate environmental strategy and the development of competitively valuable organizational capabilities. Strategic Management Journal, 19: 739-753

Stoll-Kleemann, S., and Welp, M. 2006. Towards a more effective and democratic natural resources management. In Stoll-Kleemann, S., and Welp, M. (eds.). Stakeholder Dialogues in Natural Resources Management. Heidelberg: Springer-Verlag, 17-40.

Thomas, A., and R. Simerly. 1994. The chief executive officer and corporate social performance: an interdisciplinary examination. Journal of Business Ethics, 13(12): 959-968.

Turban, D. B., and Greening, D. W. 1996. Corporate social performance and organizational attractiveness to prospective employees. Academy of Management Journal, 40: 658-672.

Tushman, M., and Nadler, D. 1978. Information processing as an integrating concept in organizational design. Academy of Management Review, 3(3): 613-624.

Ulrich, W. 1983. Critical heuristics of social planning. A new approach to practical philosophy. Bern: Haupt, 1994 reprint edition, Chichester: Wiley.

Ulrich, W. 1988. Systems thinking, systems practice, and practical philosophy: a program of research. Systems Practice, 1(2): 137-163.

Vos, J. 2003. Corporate social responsibility and the identification of stakeholders. Corporate Social Responsibility and Environmental Management, 10(3), 141-52.

Waddock, S. A., and Boyle, M-E. 1995. The dynamics of change in corporate community relations. California Management Review, 37: 125-140.

Waddock, S. A., Bodwell, C., and Graves, S. 2002. Responsibility: the new business imperative. Academy of Management Executive, 16(2): 132-148.

Waldman, D. A., Sully de Luque, M., Washburn, N., and House R. J. 2006. Cultural and leadership predictors of corporate social responsibility values of top management: a GLOBE study of 15 countries. Journal of International Business Studies, 37(6): 823-837.

Walker, E-J. 2005. Transitioning from charity to community investment at Marks \& Spencer, Corporate Responsibility Management, 1(6): 26-29.

WBCSD. 2001. Corporate social responsibility - narrowing the focus. WBCSD News, available at http://www.wbcsd.org.

Weick, K. 1979. The social psychology of organizing. Reading, MA: Addison-Wesley.

Werther, W., and Chandler, D. 2005. Strategic corporate social responsibility: stakeholders in a global environment. Thousand Oaks, CA: Sage Publications. 
Wood, D. J. 1991. Corporate social performance revisited. Academy of Management Review, 16(4), 691-718.

Zyglidopoulos, S. 2002. The social and environmental responsibilities of multinationals: evidence from the Brent Spar case. Journal of Business Ethics, 36(1/2): 141-151. 